DOI: 10.12731/2658-6649-2019-11-5-2-146-151

УДК 616.895.4

\title{
ВЛИЯНИЕ ВЫРАЖЕННОСТИ ТРЕВОЖНО-ДЕПРЕССИВНЫХ РАССТРОЙСТВ НА КАЧЕСТВО ЖИЗНИ БОЛЬНЫХ АРТЕРИАЛЬНОЙ ГИПЕРТОНИЕЙ
}

Яскевич Р.А., Кочергина К.Н., Каспаров Э.В.

Изучены особенности влияния тревожно-депрессивных расстройств на качество жизни (КЖ) у 145 больных с артериальной гипертонией (АГ). Использовалась госпитальная шкала тревоги и депрессии (HADS). Для исследования КЖ использовалась методика, разработанная Гладковым А.Г с соавт. (1982). Выявлена высокая частота встречаемости тревожно-депрессивной симптоматики среди больных с АГ. Среди лии с клинически выраженной тревогой и депрессией встречалось наибольшее количество пачиентов со значительным снижением КЖ.

Ключевые слова: артериальная гипертония; качество жизни; тревога; депрессия.

\section{EFFECT OF EXPRESSION OF ANXIETY-DEPRESSIVE DISORDERS ON THE QUALITY OF LIFE IN PATIENTS WITH ARTERIAL HYPERTENSION}

\section{Yaskevich R.A., Kochergina K.N., Kasparov E.V.}

The features of the influence of anxiety-depressive disorders on quality of life were studied in 145 patients with arterial hypertension. The hospital anxiety and depression scale (HADS) was used. For the study of QOL, a technique developed by Gladkov A.G. and others was used. (1982). A high incidence of anxiety-depressive symptoms among patients with hypertension was revealed. Among those with clinically significant anxiety and depression, the greatest number of patients were found with a significant decrease in QOL.

Keywords: Arterial hypertension; quality of life; anxiety; depression. 


\section{Введение}

Современные исследования свидетельствуют, что депрессивные и тревожные расстройства попадают в число одних из самых распространенных патологических нарушений среди населения [2, с. 10, 7, с. 672], которые негативно влияют на состояние здоровья людей [1, с. 24, 2, с. 10]. Эти расстройства чаще встречаются среди лиц трудоспособного возраста, что оказывают негативное влияние на качество жизни пациентов [6 c. 279], ухудшают физическую, психологическую и социальную адаптацию $[3$, c. 3,4, с. 64,5, c. 2$]$ и приводят к негативным социально-экономическим последствиям [1, с. 24].

\section{Цель}

Изучить влияние тревоги и депрессии на КЖ больных АГ.

\section{Материалы и методы исследования}

Для выполнения поставленной цели было обследовано 145 больных с АГ. Выявление и оценку степени тяжести тревоги и депрессии проводили с использованием госпитальной шкала тревоги и депрессии (HADS). Для исследования КЖ использовалась методика, разработанная Гладковым А.Г. с соавт. (1982). Представленная методика позволяет оценить отношение больного к изменениям в его жизни, связанными с заболеванием и ее лечением.

\section{Результаты и обсуждение}

Показано, что в целом у больных с АГ средний показатель уровня тревоги по шкале HADS соответствовал субклинически выраженной тревоге. Показатели депрессии также соответствовали субклинически выраженному уровню. Среди мужчин средний показатель уровня тревоги был статистически значимо ниже чем у женщин: 5,5 балла vs $8,7(\mathrm{p}=0,001)$. Уровень депрессии так же был ниже у мужчин. Средний показатель составил $6,0$ vs 8,5 у женщин ( $\mathrm{p}=0,001)$. Анализ частоты встречаемости различных уровней тревоги и депрессии показал, что среди обследованных у $23,8 \%$ выявлен субклинический выраженный уровень тревоги, у 20,5\% клинически выраженный уровень. У $33,6 \%$ обследованных наблюдалась субклинически выраженная депрессия, у 20,5\% - регистрировался клинически выраженный уровень депрессии. При исследовании показателей КЖ установлено, что средний показатель уровня КЖ (СПКЖ) равнялся $-5,5$ балла, что соответствовало умеренному снижению КЖ данной категории 
обследуемых. Наблюдались различия по полу. Среди мужчин СПКЖ был выше чем у женщин: $-4,9$ балла vs $-5,7$ соответственно $(\mathrm{p}=0,24)$. Анализ частоты встречаемости уровней КЖ выявил следующее: не имели снижение КЖ 9,3\% обследованных, снижение КЖ легкой степени отмечалось у $37,2 \%$ пациентов, умеренное снижение КЖ выявлено у 26,7\% и значительное снижение КЖ у 26,7\% обследованных соответственно. Установлено, что у половины больных АГ с субклинически выраженным уровнем тревоги выявлены показатели КЖ соответствующие легкому снижению, в то время как среди лиц с клинически выраженной тревогой по шкале HADS чаще встречались пациенты, с умеренным и значительно сниженным КЖ. Установлена зависимость влияния выраженности депрессии на показатели КЖ. У больных АГ с показателями депрессии по шкале HADS соответствующие нормальными значениям отмечалось наименьшее количество пациентов со значительным уровнем снижения КЖ $(8,8 \%)$, в то время как у больных с депрессией по шкале HADS соответствующей клинически выраженной, наибольшим было количество лиц со сниженным уровнем КЖ $(41,9 \%)$.

\section{Заключение}

Выявлена высокая частота встречаемости тревоги и депрессии среди больных с АГ, а СПКЖ у этих больных соответствовал умеренному снижению КЖ. Среди обследованных больных с клинически выраженными тревожно-депрессивными расстройствами чаще выявлялись пациенты с значительно сниженными уровнями КЖ.

\section{Список литературы}

1. Давыдов Е.Л., Ульянова И.О. Медико-социальные аспекты больных артериальной гипертонией в пожилом возрасте // Клиническая геронтология. 2016. T. 22, № 9-10. C. 24-25.

2. Деревянных Е.В., Балашова Н.А., Яскевич Р.А., Москаленко О.Л. Частота и выраженность тревожно-депрессивных нарушений у студентов медицинского вуза // В мире научных открытий. 2017. Т. 9. № 1. С. 10-28.

3. Разумов А.Н., Бобровницкий И.П., Колесникова И.В. и др. Влияние электромагнитных полей на тонус церебральных сосудов и артериальное давление // Вопросы курортологии, физиотерапии и лечебной физической культуры. 2006. № 2. С. 3-5.

4. Ремизов Е.В., Давыдов Е.Л., Корепина Т.В. Проблемы КЖ пациентов старших возрастных групп с артериальной гипертонией // Военно-медицинский журнал. 2012. № 5. С. 64. 
5. Филимонова Л.А., Борисенко Н.А., Алексеев И.А. и др. Мониторинг КЖ у пациентов артериальной гипертонии старших возрастных групп // Coвременные проблемы науки и образования. 2017. № 1. С. 2.

6. Яскевич Р.А., Игнатова И.А., Шилов С.Н. и др. Влияние тревожно-депрессивных расстройств на качество жизни слабослышащих мигрантов Крайнего Севера в период реадаптации к новым климатическим условиям // Современные проблемы науки и образования. 2014. № 4. С. 279.

7. Яскевич Р.А., Хамнагадаев И.И., Деревянных Е.В. и др. Тревожно-депрессивные расстройства у пожилых мигрантов Крайнего Севера в период реадаптации к новым климатическим условиям // Успехи геронтологии. 2014. T. 27. № 4. C. 672-677.

\section{References}

1. Davy`dov E.L., Ul`yanova I.O. Mediko-social`ny`e aspekty` bol’ny`x arterial'noj gipertoniej v pozhilom vozraste [Medical and social aspects of patients with arterial hypertension in old age] // Klinicheskaya gerontologiya [Clinical gerontology]. 2016. T. 22, № 9-10. S. 24-25.

2. Derevyannyh E.V., Balashova N.A., Yaskevich R.A., Moskalenko O.L. CHastota i vyrazhennost' trevozhno-depressivnyh narushenij u studentov medicinskogo vuza [The frequency and severity of anxiety-depressive disorders in medical students] // V mire nauchnyh otkrytij [In the world of scientific discoveries]. 2017. T. 9. № 1. S. 10-28.

3. Razumov A.N., Bobrovnickij I.P., Kolesnikova I.V. i dr. Vliyanie elektromagnitnyh polej na tonus cerebral'nyh sosudov i arterial'noe davlenie [The influence of electromagnetic fields on the tone of cerebral vessels and blood pressure] // Voprosy kurortologii, fizioterapii i lechebnoj fizicheskoj kul'tury [Questions of balneology, physiotherapy and physical culture]. 2006. № 2. S. 3-5.

4. Remizov E.V., Davydov E.L., Korepina T.V. Problemy kachestva zhizni pacientov starshih vozrastnyh grupp s arterial'noj gipertoniej [Problems of quality of life of patients in older age groups with arterial hypertension] // Voenno-medicinskij zhurnal [Military Medical Journal]. 2012. № 5. S. 64.

5. Filimonova L.A., Borisenko N.A., Alekseev I.A. i dr. Monitoring kachestva zhizni u pacientov arterial `noj gipertonii starshix vozrastny`x grupp [Monitoring the quality of life in patients with arterial hypertension in older age groups] // Sovremenny`e problemy` nauki i obrazovaniya [Modern problems of science and education]. 2017. № 1. S. 2.

6. Yaskevich R.A., Ignatova I.A., Shilov S.N. i dr. Vliyanie trevozhno-depressivnyh rasstrojstv na kachestvo zhizni slaboslyshashchih migrantov Krajnego 
Severa v period readaptacii k novym klimaticheskim usloviyam [The influence of anxiety-depressive disorders on the quality of life of hearing impaired migrants of the Far North in the period of adaptation to new climatic conditions] // Sovremennye problemy nauki i obrazovaniya. [Modern problems of science and education]. 2014. № 4. S. 279.

7. Yaskevich R.A., Hamnagadaev I.I., Derevyannyh E.V. i dr. Trevozhno-depressivnye rasstrojstva u pozhilyh migrantov Krajnego Severa v period readaptacii $\mathrm{k}$ novym klimaticheskim usloviyam [Anxiety and depressive disorders in elderly migrants of the Far North in the period of adaptation to new climatic conditions] // Uspekhi gerontologii. [Advances in gerontology]. 2014. T. 27. № 4. S. 672-677.

\section{ДАННЫЕ ОБ АВТОРАХ}

Яскевич Роман Анатольевич, доцент кафедры пропедевтики внутренних болезней и терапии, ведущий научный сотрудник, кандидат медицинских наук, доцент

ГБОУ ВПО «КрасГМУ им. проф. Ф.В. Войно-Ясенеикого» МЗ РФ; Федеральное государственное бюджетное научное учреждение «Научно-исследовательский институт медичинских проблем Севера» ул. Партизана Железняка, 1а, г. Красноярск, 660022, Российская Федерация; ул. Партизана Железняка, 32, г. Красноярск, 660022, Российская Федерачия cardio@impn.ru

Кочергина Ксения Николаевна, студентка 6 курса Лечебного факультета КрасГМУ им. проф. Ф.В. Войно-Ясенецкого ГБОУ ВПО «КрасГМУ им. проф. Ф.В. Войно-Ясенеикого» МЗ РФ ул. Партизана Железняка, 1a, г. Красноярск, 660022, Российская Федерация ko4ergina.ksen@gmail.com

Каспаров Эдуард Вильямович, д.м.н., профессор, директор НИИ МПС ФИЦ КНЦ СО РАН, зам. директора ФГБНУ «Федеральный исследовательский центр «Красноярский научный центр СО РАН» Научно-исследовательский институт медииинских проблем Севера, Федеральное государственное бюджетное научное учреждение "Федеральный исследовательский иентр «Красноярский научный иентр Сибирского отделения Российской академии наук» 
ул. Партизана Железняка, 32, г. Красноярск, 660022, Российская Федераиия impn@impn.ru

\section{DATA ABOUT THE AUTHORS}

Yaskevich Roman Anatolyevich, associate professor at department of propedeutics of internal diseases and therapy, leading researcher, candidate of medical science, docent

Krasnoyarsk State Medical University named after Professor V.F. Voino-Yasenetzkiy; Federal State Budgetary Scientific Institution «Scientific Research Institute of medical problems of the North» 1a, P. Zheleznyaka St., Krasnoyarsk, 660022, Russian Federation; 3g, Partizan Zheleznyaka str., Krasnoyarsk, 660022, Russian Federation cardio@impn.ru

Kochergina Ksenia Nikolaevna, 6th year student of the Medical faculty Krasnoyarsk State Medical University named after Professor V.F. Voino-Yasenetzkiy

1a, P. Zheleznyaka St., Krasnoyarsk, 660022, Russian Federation ko4ergina.ksen@gmail.com

Kasparov Eduard Vilyamovich, MD, professor, Director

Scientific Research Institute of medical problems of the North, Federal Research Center "Krasnoyarsk Science Center» of the Siberian Branch of the Russian Academy of Sciences

3d, P. Zheleznyaka St., Krasnoyarsk, 660022, Russian Federation impn@impn.ru 